\title{
ESQUEMA DE LA PREHISTORIA CHILENA Julio Montané
}

Las teorías entorno al origen del hombre en Chile formuladas con anterioridad a las investigaciones arqueológicas en el país, han sido resumidas por Medina en su notable obra Los aborígenes en Chile. Hoy indudablemente nos parecen anecdóticas y sólo tienen un valor para ilustrar la historia de nuestra prehistoria (Medina 1882, cap. II). A las opiniones allí expuestas se podrían sumar muchas otras como v. gr. La del Abate Molina, que creía que el hombre había llegado a Chile a nado desde Polinesia, o como la popularizada desde Australia a través del continente helado (Rivet 1960).

El primer cuarto de siglo, como así gran parte del segundo estarán decididamente influenciadas por los planteamientos cronológicos de Uhle que no llevan la edad del hombre en Chile más allá de comienzos de nuestra era (Uhle 1917, 1918). Casi 20 años más tarde Latcham (1936). En 1938 Bird postuló en más de cinco mil años la ocupación del hombre para el extremo sur de Chile (Bird 1938). Pudiera ser que esta hipótesis llevara a Latcham a sostener en el Congreso de Americanistas de Lima de 1941 una edad de hasta seis mil años para la capa más profunda de Taltal (Latcham 1941), quedando abierto ya el camino para proponer una antigüedad del hombre en Chile mayor a las anteriores propuestas.

$\mathrm{Al}$ estado actual de las investigaciones las evidencias no son muy claras para poder esta- blecer con certeza el trayecto seguido por tempranos pobladores de Chile.

Dichas evidencias son históricamente escasas y se pueden resumir en tres grupos: 1) Hipótesis sobre escasos materiales más documentados; 2) Interpretaciones de yacimientos superficiales y 3) Materiales bien documentados en posición estratigráfica. El único grupo de datos de valor científico fehaciente es el tercer grupo que nos permitirá plantear la realidad actual del periodo temprano en Chile.

Si bien en Chile se plantea ya en época temprana la discusión sobre la existencia de "litos paleolíticos" la investigación ha sido más bien escasa en torno a las culturas de cazadores que tuvieron una profundidad cronológica.

Treinta años después de la conmoción que provocaran los descubrimientos hechos en Taltal por Capdeville se investigan en nuestro territorio nacional las primeras ocupaciones del extremo continental de Sudamérica a través de brillantes trabajos efectuados por Junius Bird (A) Este mismo investigador haría muy pronto en la Costa Norte de Chile excavaciones estratigráficas que entregarían una profunda secuencia para los concheros de la zona (B).

Aunque en los últimos 10 años se han intensificado los trabajos sobre sitios superficia- 
les correspondientes a cazadores en los que se han hecho importantes recolecciones, se carece de nuevas excavaciones. Respecto a los sitios de recolectores de economía marítima y pescadores, las nuevas investigaciones son bastantes más recientes y solamente en estos últimos años se ha despertado un interés por hacerlas con las técnicas requeridas.

La arqueología chilena ha descansado siempre en un número muy reducido de investigadores quienes contaban con muy exiguos medios para llevar a cabo trabajos exhaustivos. Pese a que esta última situación no ha variado fundamentalmente se vienen incorporando nuevos investigadores a partir de hace 10 años. En la actualidad se ha incrementado bastante la investigación a través de la profesionalización de la actividad arqueológica. Por otra parte la renovación que ha experimentado la arqueología en países hermanos ha tenido benéfica influencia en la intensificación de los trabajos de Chile. Los cinco congresos de arqueología efectuados en Arica, San Pedro de Atacama, Viña del Mar, Concepción y La Serena han permitido toda una interacción impulsadora de actividades a la que debe agregarse los cursos que se efectúan en la Universidad de Chile y la Universidad de Concepción la cual ya cuenta con un primer grupo de egresados.

El lapso que media entre los trabajos de Bird y los de los últimos años podría explicar en parte el que estas investigaciones, como veremos a continuación, no hayan servido siempre de guía, quizás por el peso de las tradiciones de las antiguas modalidades empleadas por los primeros investigadores, ya que los trabajos de estos estaban a mano de los investigadores chilenos y otra parte eran una visión total de la arqueología chilena.

Tal es así que en torno a los descubrimientos de sitios superficiales en el norte de Chile no se han aplicado las enseñanzas que arrojaron las secuencias establecidas para el extremo austral. Si bien Chile es el primer país sudamericano y de esto hace unos 30 años que muestra una clara secuencia ocupacional basada en excavaciones estratigráficas del desarrollo de las culturas de cazadores, debemos reconocer que en general no hemos sabido afianzar estas evidencias para otras partes del país.
Estando probada con claridad la conveniencia del hombre con fauna pleistocénica extinguida (caballo fósil americano, por ejemplo) no se ha indagado mayormente en este sentido.

La secuencia arqueológica en Chile es sin duda la más completa que posee Sudamérica y que revela, en un periodo de 11000 años a partir de la actualidad, cinco secuencias culturales en una docena de capas estratigráficas, para la zona austral de su territorio continental. Esta secuencia estratigráfica es fundamental para comprender el desarrollo de las culturas más tempranas en nuestro territorio y los datos arrojados por ella deben ser valorizados mucho más de lo que lo ha sido hasta la actualidad.

En los últimos 8 años se han multiplicado las investigaciones para el norte de Chile y se han ubicado, por lo tanto, también muchos yacimientos precerámicos que se han supuesto superficialmente, lo que no es necesariamente cierto. Se confeccionaron secuencias de culturas, tradiciones e industrias que parecen dar un panorama muy completo de la sucesión de las culturas de cazadores para el área. Las cronologías se caracterizaron primeramente para atribuir bastante antigüedad a estos hallazgos. Le Paige incluso sostuvo edades superiores a los 40 mil años para los primeros cazadores de la zona. Posteriormente dejar constancia que en los múltiples trabajos sobre el precerámico de norte de Chile no se hagan mayores referencias a las secuencias establecidas por J. Bird para los cazadores australes.

En ningún trabajo se ha planteado la evidente posibilidad de que las primeras ocupaciones correspondieron a cazadores portadores de las tradiciones que los investigadores de las tradiciones que los investigadores norteamericanos denominan paleoindianas como lo hacíamos notar en otra oportunidad (Montané 1967). Muy al contrario se ha postulado la presencia de cazadores que serían anteriores a esa tradición y que se caracterizarían por carecer de puntas de proyectil, siendo que 8 mil años a.C. ocupaban nuestro territorio cazadores portadores de la tradición de puntas con acanaladuras en la base y mitad del cuerpo de las puntas con una terminación en cola de pescado y asociadas a la fauna fósil. Sólo en la 
meritoria monografía sobre Intihuasi de A. R. González (González 1960) se hacen referencias a las secuencias de J. Bird; allí también se incluye un trabajo del propio Bird (Bird 1960) en el que se compara un tipo de puntas de Fell con las Ayampitín. Este es un aspecto que necesita una pronta indagación, puesto que es indudable que fuera del extremo sur y el sitio de Inga deben encontrarse otros yacimientos.

Una segunda conclusión importante que arrojan estas investigaciones es que los elementos toscos, se encuentran en un nivel superior y por tanto son posteriores al periodo con puntas de las excavaciones de Junios Bird. No deja de llamar la atención que esta circunstancia haya sido desconocida por la mayoría de los investigadores, especialmente los chilenos que han tratado el tema del precerámico. Como es bien sabido, el segundo periodo de los cazadores australes no posee puntas de proyectil líticas. Estas fueron confeccionadas en hueso. Si dichos elementos culturales son ubicados en un sitio superficial no se encontrarían las puntas de hueso y por lo tanto, pueden ser interpretados incorrectamente como elementos asimilables a una cultura que no poseía puntas de proyectil. A pesar de las evidencias señaladas se han forzado en tal forma los hechos en el yacimiento de Gatchi, que las múltiples puntas que allí se encuentran se han separado del resto de los materiales atribuyéndolas a priori a una segunda fase, más reciente, mientras que una primera fase no existirían puntas de proyectil. Así asimilando estos elementos a un posible horizonte anterior al de puntas, como si hubiera base para dividir las culturas en horizontes con y sin puntas o prepuntas y postpuntas, cabe preguntarse: ipor qué no?

Otro aspecto en nuestra opinión más grave tiene que ver no ya con el desconocimiento de los trabajos sobre nuestro propio país sino con el desconocimiento de elementos normales exigidos para el trabajo científico. A decir verdad esto no es culpa de los investigadores chilenos solamente ya que los investigadores de fama, o que por lo menos publican en prestigiosas revistas y suelen ser citados con cierta frecuencia, creen poder datar los litos trabajados sin que posean antecedentes estratigráficos sobre su procedencia y pretenden plantear en secuencias cronológicas en base a "tipologías" que se caracterizan en general por una supuesta evolución que va desde los artefactos más toscos a los más perfeccionados. Me consta que la supuesta secuencia postulada por Le Paige se afirma en opiniones de Menghin y Krieger (Menghin 1963, Frieger 1964) y más recientemente en las de Lanning (Lanning 1967).

Por esto no debe de extrañarnos que los materiales recogidos superficialmente, muchas veces en forma selectiva, sirvieran de base para bautizar "industriales", "complejos" y "culturales" tanto en las zonas desérticas y semiáridas como en el valle central. El autor describió hace algunos años seis artefactos encontrados en la superficie de una terraza litoral. No le dio naturalmente ningún fechado (Montané 1960). Años después Menghin creyó en base a la citada publicación que debía tratarse de un epiprotolítico (Riogalleguense II) con una edad de 6000 a 10000 años (Menghin 1962). Se podrían multiplicar los ejemplos que saltan a la vista al revisar un notable trabajo de Schobinger en el que se resume la prehistoria de Sudamérica. (Schobinger 1969).

\section{YACIMIENTOS ESCASOS MATERIALES MAL DOCUMENTADOS}

Liguay. - Según Medina, cercana a la localidad de Liguay se habría hallado a tres metros de profundidad en una capa de cascajo una biface que "es el ejemplar más interesante de todos los que poseemos hasta ahora por la gran antigüedad que indudablemente tiene" (Medina p. 420 ed. 1952). No conocemos el original ni hay certificación de hallazgo, este es anterior a 1882 y sería el único artefacto encontrado en una gravea. No se le puede atribuir por lo tanto, ninguna edad ni debe ser tomado en cuenta como indicio de la presencia temprana del hombre en Chile. No es tampoco citado otros autores.

Arica.- Escasos elementos superficiales fueron encontrados por Uhle en Arica y atribuidos al Hombre Primordial (Uhle 1922 y Latcham 1936). La existencia del Hombre Primordial corresponde más bien a una construcción y no a una realidad que se puede sustentar en hallazgos. Debe descartarse el término no sólo 
por inadecuado sino también por las escasas pruebas sobre las cuales se forjó. A pesar de ello ha podido subsistir 20 años, sin que se aportaran nuevas evidencias.

Taltal.- A partir de los descubrimientos hechos por Capdeville en Taltal y la discusión en torno a éste efectuado por Uhle y Latcham, se escribió mucho sobre elementos paleolíticos para este sitio. La supuesta existencia de elementos paleolíticos unidos a una economía marítima de recolectores y pescadores fue dilucidada en forma definitiva por Bird (Capdeville 1921, 1928; Uhle 1916; Letcham 1915; Oyarzún 1916 y Mostny 1964) (Bird 1943). Posteriormente, sin nuevas excavaciones de orden estratigráfico, se ha insistido en que los elementos encontrados en Taltal corresponderían a tradiciones tempranas de cazadores, (Berdichewsky 1963; Orellana 1960; Le paige y Krieger 1964).

Recientemente Bird constató a Krieger insistiendo en que las evidencias arqueológicas que no han sido tomadas en cuenta debidamente por diversos autores, se hallan no obstante en todos los niveles del conchero de Taltal, incluso en estratos correspondientes a épocas agrícolas con cerámica (Bird).

Tierras Blancas.- En una yesera cerca de la localidad de La Ligua se habrían hallado dos cráneos humanos cerca de un mastodonte. Encontrándose estos restos depositados en museo, estamos a la espera que se efectúen los análisis que permitan indicar si los restos humanos son contemporáneos o no con la fauna fósil (Oyarzún 1971; Fuenzalida 1936).

Chacabuco.- En 1929 a $30 \mathrm{~km}$ al norte de la capital se ubicaron restos de caballo y mastodontes aparentes en relación con puntas de proyectil, asociación que Latcham consideró accidental, al suponer que el material lítico era intrusito de las capas superficiales (Informaciones en diarios de la época). La escasez de evidencias inducen a descartar este tipo mientras nuevas investigaciones no aporten otras pruebas más concluyentes.

Cueva del Milodón.- A pesar de que se revive de tanto en tanto los hallazgos efectuados en esta gran caverna y gracias a la insistencia pri- mero de Manghin y luego de Schobinger, sobre la posible asociación de industria con la fauna extinta, nadie ha probado tal relación como lo indican los arqueólogos que más recientemente han excavado la cueva (Schobinger 1959; Bird 1938; Emparaire y Lanning 1954). Por de pronto el sitio debe desecharse como prueba de un doblamiento temprano mientras nuevas evidencias de excavaciones controladas no demuestran lo contrario.

\section{INTERPRETACIONES DE YACIMIENTOS SUPERFICIALES}

Gatchi.- Para el sitio de Gatchi, Le Paige ha estipulado una antigüedad que sobrepasa los 40.000 años, partiendo del presupuesto de que los elementos toscos del yacimiento corresponden al horizonte más primitivo ingresado a América que se caracteriza por su carencia de puntas de proyectil. Debe reconocerse que los planteamientos de algunos investigadores han dado motivo para que Le Paige pensara que se podía proponer una fecha más antigua. Tanto investigadores chilenos como extranjeros han insistido en la necesidad de rebajar esta fecha, pero creo como ya se había planteado una gran antigüedad de todas maneras resultó que Gatchi era la industria más antigua del Norte de Chile. Contribuyeron a reafirmar la idea los planteamientos de Le Paige y especialmente Orellana, de que Gatchi se dividía en 2 fases. En el primer periodo no existirían las puntas de proyectil (que son relativamente abundantes en el sitio), en cambio aparecerían como rasgo característico dentro de un segundo periodo.

Nos encontramos ante el argumento ingenuo de la tapa de Cola-Cola, que se expresa en síntesis que si en la superficie se encuentra una tapa metálica de un recipiente de bebida no debe relacionarse con el material lítico que se encuentre junto a ella, y por la misma razón las puntas de proyectil no debe asociarse a los elementos toscos como las supuestas "hachas de mano" de Gatchi. Hay que reconocer que así se facilita el trabajo del arqueólogo ya que debe tener solo cierta habilidad para separar de una colecta los diferentes periodos para postular toda una cronología de esta área. Posteriormente se procederá, entonces, a considerar que es contemporáneo con otro yaci- 
miento que también presenta materiales toscos y tendremos abierto el camino para todo un horizonte en que las supuestas fechas de un sitio servirán para datar otros, o viceversa, que sobre estos fechados tentativos se construirán cronologías para cualquier lugar. Aunque el autor sienta tener que decirlo, callarlo sería faltar a la verdad. Por ahora mientras que no se presenten evidencias estratigráficas que arrojen un fechado aceptable, debe ser rechazada tal división y la antigüedad atribuida a estos elementos (Montané 1967 p. 7) (Le Paige Orellana).

Complejo Chuqui.- El complejo Chuqui fue determinado por Lanning en base a yacimientos superficiales ubicados en el Salar de Talabre (Lanning y Patterson 1967). Tendría una edad de 14.000 años y tipológicamente es semejante al material proveniente de la Zona Roja de Chiveteros.

Recientemente Meltzar lo ha dividido en dos fases basándose en consideraciones tipológicas (En comunicación Simposio San Pedro de Atacama, diciembre 1969). Puesto que la gran mayoría de los elementos recolectados son podolitos que sólo se encuentran en la huella tropera que surca el salar, tenemos serias dudas sobre las investigaciones efectuadas en dicho salar que nos las reservamos mientras no se encuentre este complejo en un nivel que se pueda considerar cultural.

Complejo Talabre.- El Salar de Talabre posee múltiples talleres en los sitios en que aflora la materia prima que sirvió para la elaboración de artefactos. Fue reconocido hace 10 años por Barfield, más recientemente por Núñez y lo trabajó durante un largo periodo la Universidad de Columbia. Se encuentra situado cerca de la localidad de Chui-Chui a unos $7 \mathrm{~km}$ del río Loa. Aquí nos encontramos con una de las tantas disquisiciones sobre el clima que debió haber existido para que el hombre viviera en esos lugares. Si es que alguna vez vivió allí, en consideración a que en el Salar el hombre no puede soportar hoy la vida (Meltzar) y que por lo tanto hay que pensar en qué posibles condiciones de clima el hombre podía disponer de recursos suficientes. Esto nos lleva muy pronto a pensar en el final del Pleistoceno (Meltzar). Desgraciadamente no existen estudios sobre el paleoclima para el Norte del país, y por lo tanto las consideraciones sobre él deben considerarse como hipótesis tentativas. Por otra parte, la existencia del río Loa en las cercanías indudablemente permite al hombre un fácil acceso a los recursos de materia prima del Salar. Por ende no se necesitan mayores consideraciones climáticas para suponer la existencia de talleres en cualquier momento temporal en que el río presentara recursos hidráulicos. De aquí que basar los cuatro momentos de Talabre que postula Lanning en secuencias que se relacionarían con posibles niveles del lago que habría sido contemporáneo con el hombre, carece de fundamento, porque a la fecha no se ha demostrado la existencia de diferentes niveles del lago en relación con la ocupación humana (Schobinger 1969). La distinción de los 4 Talabres es meramente tipológica, ya que se pueden encontrar en un mismo taller las distintas fases. Desgraciadamente los materiales que han servido para construir esta tipología no se encuentran en el país, de modo que es difícil pronunciarse en detalle sobre ella. Si bien Meltzer considera que la comparación de las bifaces de las fases I y II es como la diferencia que hay entre el Acheulense y el Abbevillense. Las únicas evidencias estratigráficas seguras para este tipo de bifaces para el Norte del país son las del sitio de Conanoxa, con una edad de 3740 más menos 130 (Schiappacasse y Niemeyer 1969) y la del nivel superior de Tagua para la zona central, con una edad de alrededor de 6000 años (Montané 1969): Curiosamente Meltzer, al hacer estas consideraciones, desconocía la monografía sobre Conanoxa en que aparecen descritas diferentes bifaces asociadas en un mismo nivel ocupacional.

Creo que nos encontramos, al igual que respecto a Gatchi con un problema elemental de metodología sobre el cual no es necesario insistir.

Loma Negra.- Corresponde Loma Negra a un taller con evidencias de ocupación hasta el periodo reciente, y no existe ninguna razón que permita asimilarlo al supuesto Gatchi I, por lo que debe ser descartado por ahora como sitio temprano, mientras no se hagan investigaciones en el lugar.

Puripica, Tulán, Tambillo, Sonoral, Huasco.También se trata de sitios superficiales consi- 
derados más tardíos que los anteriores y que pueden serlo, como que igualmente podrían ser más tempranos. Deben ubicarse en posición estratigráfica o en un nivel que de seguridad sobre cual es el verdadero contexto ergológico. Podríamos anotar que en investigaciones inéditas de Niemeyer y Schiappacesse presentadas en el IV Congreso de Arqueología de Chile se encuentran en asociaciones materiales atribuidas a Tambillos con los considerados para los cuales se ha postulado diferencias temporales de 3000 años (II Congreso de Arqueología Chilena).

\section{MATERIALES BIEN DOCUMENTADOS EN POSICIÓN ESTRATIGRÁFICA Y FECHADOS}

Para la materia de nuestro interés desgraciadamente no son muchos los sitios excavados con cierta sistematización y que presenten niveles definidos de los cuales se hayan obtenido fechados absolutos, que estén publicados o se hayan dado cuenta de ellos con cierto detalle.

Aquí consideraremos los sitios del extremo sur Cueva Fell y Cueva de Palli Aike; una para la zona central: Tagua-Tagua, uno para el norte chico: el abrigo de San Pedro Viejo de Pichasca y uno para el norte grande: Conanoxa, que incluimos a pesar de su fechado reciente, en consideración a los instructivo que puede ser para el examen de supuestas industrias tempranas.

Cuevas de Fell y Palli Aike.- Basándose en las excavaciones de varios sitios en el área del Estrecho de Magallanes, Junius Bird pudo establecer en 1938 una secuencia de 5 periodos para el desarrollo cultural de los grupos de recolectores y cazadores pedestres del extremo Sur (Bird 1938). De estos yacimientos los más importantes y de los que se poseen fechados absolutos son las Cuevas de Fell y Palli Aike.

Un primer periodo datado en 11.000 años (Bird 1970) se caracteriza por las puntas de proyectil denominadas "cola de pescado" (Bird 1969), raspadores terminales y laterales, retocadores, chopping-tools (tajadores groseros), discos de uso desconocido, etc. (Bird 1946).
Las puntas de proyectil de tipo "cola de pescado" han sido detectadas superficialmente en otros sitios: Aysén en Chile, El Inga en Ecuador. Departamento Flores en Uruguay (Bird 1969) Santa Catarina en Brasil (Rohr 1966). Lo que no es muy seguro puesto que sólo conocemos un dibujo. Parece ser que en Río Limay también puede considerarse su presencia (Vignati) y, por último, Sander describe una para Panamá. Ninguno de los sitios señalados permite establecer una cronología aceptable y por ende no puede sostenerse que las puntas de proyectil allí ubicadas sean contemporáneas con las de las cuevas magallánicas. Hace excepción la punta tipo "cola de pescado" de Los Toldos (Menghin 1952) hallada en posición estratigráfica y que debe correlacionarse seguramente con el periodo I de la secuencia magallánica (Bird 1970).

Los primeros ejemplos ilustrados por Bird no muestran acanaladura, en cambio sí la tienen los colectados por J. Fell y Emperaire (Emperaire 1963 y Bird 1969). Es decir, se presentaría dos variedades: con y sin acanaladura, siendo por ahora las primeras más frecuentes en las Cuevas de Fell y Pallu Aike. Un segundo tipo está constituido por un solo ejemplar que debe de considerarse más bien como un producto casual al aprovechar, según parece, una lasca a la cual se podía acondicionar con pocos retoques como punta de proyectil. Las conclusiones a que ha llagado Menghin en el sentido de pensar que se trataría de una punta folsomoide, se basan en lo expresado por Bird y se deben a un error involuntario de este investigador por la interpretación de la fotografía poco nítida que da la impresión de un rebaje intencional que no existe como tal en el original (Menghin 1952). No debe descartarse la eventual posibilidad de que en el futuro este probable tipo sea más popular, especialmente si consideramos que la línea de su contorno presenta similitudes con la de algunas puntas que se encuentran en el periodo III que es donde vuelven a aparecer las puntas líticas y que por lo tanto en algún otro sitio podría hallarse una vinculación más estrecha.

Por ahora las puntas tipo "cola de pescado" son representativas de un periodo temprano sólo en el extremo sur, incluyendo a Los Toldos y es solamente una hipótesis que los diversos 
especimenes encontrados en otros lugares de Sudamérica y Centroamérica pueden asimilarse a un periodo temprano.

Es un hecho notable la aparición de los discos pulidos en un periodo tan temprano y debe llamar a reflexión a quienes suponen a los artefactos pulidos siempre como muy recientes. No podemos dejar de llamar la atención sobre la presencia de estos discos en el Norte Chico de Chile y que han sido definidos como elementos integrantes de la denominada Cultura de Huentelauquén, cuyos hallazgos superficiales no han sido datados, aunque el autor ha sostenido que su edad podría alcanzar los 6.000 años (Montané 1964).

Es importante hacer notar que ciertos elementos como los dos tipos de raspadores que se dan en este primer periodo se presentan en todos los niveles de las Cuevas de Fell y Palli Aike, excepción hecha del periodo histórico. Este hecho por demás concluyente demuestra una vez más el peligro que encierra la pretensión de datar a base de tipología los yacimientos superficiales con instrumentos líticos que se consideran asimilables a un momento temporal. Estos raspadores monofaciales tipológicamente semejantes a los de los yacimientos paleoindios de Estados Unidos de Norteamérica, tienen una fuerte supervivencia histórica, debida seguramente a la circunstancia de que grupos tempranos portadores de ellos han quedado como entidades marginales, motivo por el cual han subsistido ciertas tradiciones tanto de manufactura como de funcionalidad.

Dos fragmentos de objetos de hueso podrían corresponder a retocadores enmangados o a la parte proximal de la estólica. Por último, queremos señalar que los tajadores burdos se encuentran también en otros periodos, no teniendo por lo tanto carácter diagnóstico para los periodos. Dados estos antecedentes el único elemento diagnóstico para la fase más antigua en la Patagonia austral parece ser la punta "cola de pescado".

En resumen, en el extremo Sur de Chile nos encontramos frente a una ocupación a partir de los 11.000 años atrás la que al estado de las evidencias actuales, no puede vincularse directamente con ninguna otra del continen- te sudamericano, pese a que nadie tiene dudas acerca del hecho de que estos cazadores y recolectores del extremo Sur pasaron por el Istmo y se dispersaron por Sudamérica hasta alcanzar el Estrecho de Magallanes.

Es de esencial importancia el hallazgo de Bird de lo que él señala como un segundo periodo para la región del Estrecho de Magallanes, detectado por él en las Cuevas de Palli Aike y Fell. El rasgo más notable de este segundo periodo es la ausencia de puntas de proyectil líticas y la presencia en general de una industria "empobrecida" respecto a la que determinó para el primer periodo.

Según Bird, este periodo de las puntas de proyectil son reemplazadas por huesos aguzados que habrían desempeñado similar función (Bird 1938). Algunos autores han interpretado la carencia de puntas líticas como una prueba más de la existencia de horizonte más temprano que el primero que se caracterizaría por no poseer puntas de proyectil (Krieger 1964; Krieger 1965; Bird 1967). Tanto la posición estratigráfica como su posible datación no hablan a favor de tal teoría.

Pensamos que esta industria empobrecida corresponde a un fenómeno local. En Palli Aike, el segundo periodo se ubica inmediatamente encima de la capa de cenizas volcánicas provenientes de una gran erupción en la zona. Este accidente tectónico está representado en la cueva Fell por un desprendimiento de la bóveda que sella el primer nivel ocupacional y sobre el cual se encuentra la presencia del segundo. Creemos que esta erupción que cubrió una gran área produjo un amplio cambio en la fauna regional. El guanaco, por ejemplo, es muy abundante en el primer periodo, prácticamente desaparece en el segundo periodo, es escaso en el tercero y nuevamente en el cuarto, lo que quiere decir que por un tiempo estuvo muy débilmente representado en la zona hasta que reingresó con una popularidad tan alta como en el primer periodo.

En el segundo periodo, en cambio, hay marcada presencia de restos de ave, lo que se explica por lo fácil que debe haber sido su reingreso. Esto significa que esta empobrecida industria no es sino prueba de la adaptación del 
hombre al campo ecológico, puesto que ahora debía basar su economía en la recolección y caza menor. Otros animales como el milodón y el caballo no reingresaron a la zona por ser animales del pleistoceno final que ya no lograron subvivir en los comienzos del holoceno, tanto por los cambios del clima como por la acción de la depredación por parte del hombre.

Por otra parte, no hay ninguna evidencia que permita sustentar que la ergología de este periodo pudiera ser la supervivencia de alguna tradición. Está demás señalar que las tradiciones sólo subviven cuando son útiles al hombre para su comportamiento en un determinado medio.

El tercer periodo aún no fichado, tiene aquí importancia porque se han iniciado importantes correlaciones entre sus puntas de proyectil y las de Cueva de Intihuasi (Gonzales 1960; Bird 1960). Desgraciadamente no poseemos los datos referentes a los hitos intermedios. La edad en Intihuasi alcanza a los 9.000 años para estas puntas pedunculadas triangulares con base convexa y en Chile quizás alcancen una edad similar en la cueva de San Pedro Viejo de Pichasca en el Norte Chico.

Tagua-Tagua.- Este yacimiento que viene siendo investigado desde 1967 ha arrojado la evidencia que hace 11.000 años el hombre cazaba el mastodonte y caballo de Chile Central. En sedimentos lagunares correspondientes a una antigua orilla hemos encontrado el lugar en el que fueron faenados estos animales junto a instrumentos cortantes algunos muy toscos, y a percutores y retocadores de hueso. Los instrumentos monofaciales están retocados a percusión empleándose en algunos casos la técnica de calentamiento de las lascas al fuego antes del retoque. Aquí hallamos una vez más algunos tajadores, seguramente partidores de hueso, muy toscos, unidos a implementos muy bien elaborados (Santana, Montané 1968, 1969). En un nivel superior en el mismo sitio hallamos un estrato ocupacional de cazadores y recolectores y seguramente también de la economía marítima en el litoral del cual Tagua-Tagua dista unos $60 \mathrm{~km}$. Presenta el yacimiento una variedad de puntas pedunculadas. Unidas a estas puntas hemos colectado piedras horadadas, manos de moler, pulidores de pie- dra, instrumentos toscos, raspadores y bifaces semejantes (Montané 1969).

Mientras que el primer nivel corresponde al final del Pleistoceno en la zona central, el segundo nivel se asimila al optimum climatium, hecho certificado por un análisis de radiocarbono que arrojó un valor de $6130 \pm 115$ (I 3987). Dos nuevos fechados muestran cierta discrepancia al datar la base del nivel ocupacional de $5500 \pm 230$ (I 4964) y la parte superior del nivel en $5055 \pm 105$ (I 4965) y sobre los cuales todavía no nos pronunciamos y esperamos un informe complementario de laboratorio.

Si bien los raspadores del primer estrato presentan un aspecto y además una edad semejante a los del primer nivel de la cueva Fell, no tenemos suficientes antecedentes como para sostener que se trate del mismo grupo de cazadores tempranos. Quizás el hallazgo de puntas de proyectil entregue nuevas luces. Cosa curiosa, de los muchos investigadores que han visitado el sitio han surgido dos opiniones, unos esperan el hallazgo de las puntas y otros consideran que no encontraremos puntas. Los hechos decidirán en el futuro.

Los elementos ubicados en el segundo nivel pueden vincularse a otros muchos de la Zona Central que desgraciadamente no poseen dataciones, como son los cuchillos y raederas y puntas de proyectil encontrados en Cahuil (Montané 1960) y los materiales provenientes del sitio de Las Cenizas (Gajardo Tobar 1960). En todo caso pensamos que se trata de un grupo de recolectores y cazadores que se asentaban tanto en el litoral como en los valles interiores y cuya presencia estaría marcada en aquellos sitios donde existen morteros colectivos y un material lítico similar que cubre un periodo que va por lo menos del optimun climaticum hasta la entrada de la agricultura al área, ya dentro del marco de nuestra era (Montané, V Congreso de Arqueología Chilena).

Ya señalamos anteriormente que la biface asociada a este nivel es la más antigua que se conoce para Chile, que se encuentra unida a puntas de proyectil que muchos investigadores consideran reciente. 
Conanoxa.- Este sitio ubicado en la Quebrada de Camarones sobre una de sus terrazas, evidencia el paso de pequeños grupos transhumantes que cazaba la viscacha, colectaban camarones. Productos vegetales del valle como los frutos del llano (Prosopis juliflora var.), chañar (Gourlica decorticans). Probablemente también se cazaba el guanaco. Entre su industria se puede citar morteros, tajadores (Choppers), mano de mortero, puntas de proyectil triangulares de base convexa lanceoladas simétricas, hojas simétricas y asimétricas, hojas espesas, raspadores laterales, raspadores apicales, bifaces, etc. cestería, cueros trabajados, etc. (Niemeyer y Schiappacasse, 1965).

Muchos de estos instrumentos son toscos y tienen un aspecto primitivo la edad obtenida por análisis de radiocarbono es de $3740 \pm$ 130 (I V I C 175) (Schiappacasse y Niemeyer 1969).

Con este sitio terminamos la revisión de los sitios arqueológicos tempranos, hecha lo más sucinta posible, y si en esta enumeración hemos incluido a Conanoxa, cuya edad no sobrepasa los 4000 años, se sabe a que es el único yacimiento nortino, a excepción de los sitios costeros, que han sido datado y porque presenta materiales semejantes a los de los sitios que se han considerado tempranos para el norte de Chile.

\section{Sitios DE PESCADORES, CAZADORES Y RECOLECTORES DE ECONOMÍA MARÍTIMA}

Los sitios de economía marítima situados en el litoral son bien conocidos para el Norte y extremo austral de Chile, en especial los primeros, que se encuentran registrados en una monografía ya clásica (Bird 1943).

Los fechados de estos basurales conchíferos alcanzan hasta los 8000 - 9000 años en el extremo sur (Lanning - Emperaire 1968) y hasta los 6000 años en el extremo Norte (Bird 1967 y Mostny 1964). Del Norte chico poseemos dataciones que llegan hasta los $3760 \pm$ 110 (Schiappacasse y Niemeyer 1968). Sostenemos que para la costa central la ocupación del litoral debe remontarse a 6000 años según evidencias encontradas en Tagua-Tagua, pero no se ha fechado ningún sitio de la costa en el área correspondiente. Anteriormente postulamos que la costa comprendida entre Chile central y el extremo Norte no presentaría sitios de una edad mayor a los 6000 años, en consideración a que creíamos que los sitios de data más antigua deben encontrarse bajo el nivel de mar (Montané 1964). Una amplia bibliografía para estos sitios se hallará en las recopilaciones bibliográficas del autor. (Montané, 1963-6465-66-67-68-69).

\section{RESUMEN Y COMENTARIO}

Nuestra intención ha sido presentar a ustedes una visión del doblamiento temprano de Chile y de las culturas que se encontrarían desde la llegada de los primeros pobladores hasta el Optimun climaticum, es decir unos 6000 años antes del presente.

Al revisar los antecedentes en que fundamentamos nuestras consideraciones nos hemos encontrado con que para los grupos que podrían considerarse como cazadores y recolectores tempranos conocemos sólo dos sitios en Chile que pueden ser asignados a este momento: La Cueva de Fell y la ex-laguna de Tagua-Tagua.

Es cierto que se conoce un fechado temprano para el Norte, correspondiendo éste a la Cueva de San Lorenzo, pero desgraciadamente no se han publicado mayores noticias sobre el lugar, ni menos acerca de las asociaciones relacionadas con dicho fechado, razón por la cual no podemos tomarlo mayormente en cuenta por ahora. La datación en referencia arroja un valor de $10.280 \pm 120$ (radiocarbono 9,207).

Pese a esta escasez de sitios bien documentados es evidente que la zona central de Chile estaba habitada por cazadores de caballo y mastodonte hacia 11 mil años (GX 1205. $11,380 \pm$ y Gif $1265.11,000 \pm 300)$. Los hallazgos del Sur del país son de edad contemporánea que también puede expresarse en 11,000 años (I-3988. 11,000 $\pm 170 \mathrm{~W} 95: 10,720 \pm$ 320). La Isla Grande de Tierra del Fuego, en el sitio de Marazzi, evidencia una antigüedad cercana de los 10,000 (Gif 1034; 9,590 \pm 120 ) 
(Lanning-Emperaire 1968 a y b). Por lo tanto podemos sostener de modo concluyente que el doblamiento del continente sudamericano debe de enfocarse como en algunos milenios más antiguo que estas dataciones y que por ende hay que ubicarlo climatológicamente dentro de las fases finales del Pleistoceno. En consideración a la diversidad ecológica de las diferentes áreas de Sudamérica, los pobladores tempranos deben de haber tenido que readaptar sus utensilios a necesidades variables, de acuerdo con las rutas que siguieron y con las zonas a las que penetraban. Podría ser un buen ejemplo el cambio experimentado entre el periodo primero y segundo de la secuencia megallánica al que nos referimos anteriormente. Un factor que debe de haber retrasado el proceso de penetración por el continente hacia el sur es la obligatoriedad de gran adaptación en las zonas selváticas con el fin de poder sobrevivir y donde, por ende, las migraciones tienden a detenerse hasta cierto punto. Por otra parte hay que señalar la necesidad humana de adaptarse al consumo de las nuevas plantas comestibles, aprendiendo a conocer y evitar las nocivas. Si bien en líneas generales podemos decir que el utillaje temprano y sus técnicas para Chile se corresponden con el instrumental de los grupos denominados en América del Norte como "paleoindios", no sabemos todavía si estas similitudes se deben a tradiciones comunes o si se trata de un mismo horizonte de pobladores de doble continente. Curiosamente las fechas son en general semejantes por lo que me inclino a aceptar la primera posibilidad, ya que a tan grande distancia es difícil suponer que los cazadores, al pesar por medios distintos, hubieran conservado sus cánones de manufactura y empleo de instrumentos. Las convergencia o debe descartarse como explicación plausible.

Si bien como arqueólogos nos interesa el comportamiento humano en el pasado, consideramos muy prematuro sacar conclusiones a base de los datos disponibles hasta hoy, conclusiones que resultarían demasiado general y en consecuencia poco útiles. De todas maneras nos atrevemos a postular que la supervivencia de técnicas de manufactura y de determinados tipos de implementos en el extremo sur se explica porque los grupos tempranos de pobladores quedaron en situación marginal con respecto al desarrollo ulterior de las culturas más septentrionales.
En un país como Chile, donde es difícil hacer una diferenciación entre costa e interior ya que los valles longitudinales no distan del litoral más de $60 \mathrm{~km}$, muy pronto se desarrolló un activo tráfico entre la costa y el interior. El litoral aparentemente estuvo poblado por grupos que explotaban los recursos del mar tempranamente. Si bien en el territorio continental las fechas no sobrepasan sensiblemente los 6000 años, en el área insular las fechas hasta 9590 años (sitio de Marazzi).

Datos estos antecedentes y siempre que los datos de la Misión Francesa sean exactos, también podemos sugerir que no sólo en el litoral chileno deben existir más tempranos aumentando su antigüedad cuanto más al norte estén situados sino que también las hay en toda la costa del Pacífico. Debe entenderse que los grupos de economía marítima los cuales en la costa asiática corresponden al pleistoceno final, pueden haberse trasladado a la costa americana en época muy temprano.

Si bien para Chile se conocen restos humanos muy antiguos para el extremo Sur, estos no han sido publicados en detalle pero esperamos que pronto el antropólogo físico Juan Munizaga nos dará a conocer el estudio que tiene en preparación sobre los cráneos recuperados por Bird en Magallanes. Dicho sea de paso que la publicación de Le Paige de un maxilar fósil de San Pedro de Atacama nada tiene que ver con un maxilar humano ni con un fósil. Se trata de una concreción natural y por lo tanto este su puesto hallazgo debe ser definitivamente desechado (Le Paige 1965).

Hemos insistido, tal vez no con el debido énfasis, en el riesgo que significa el tratar de sacar conclusiones prematuras de hallazgos no bien documentados y especialmente de los sitios superficiales. Sugerimos la imperiosa urgencia del trabajo coordinado de equipo y del esfuerzo colectivo en torno a la resolución de los problemas que hoy presenta la arqueología chilena respecto del periodo en discusión. Esto no lo señalo para los investigadores chilenos, sino también para los extranjeros quienes salvo raras excepciones sin un acabado conocimiento de la realidad desean explicar esquemas preconcebidos buscando de preferencia confirmaciones antes que un estudio de la realidad chilena específicamente del pasado precolombino de Chile. 